\title{
Description of Sarcocystis lari sp. n. (Apicomplexa: Sarcocystidae) from the great black-backed gull, Larus marinus (Charadriiformes: Laridae), on the basis of cyst morphology and molecular data
}

\author{
Petras Prakas $^{1}$, Liuda Kutkiené ${ }^{1}$, Dalius Butkauskas ${ }^{1}$, Aniolas Sruoga ${ }^{2}$ and Mečislovas Žalakevičius ${ }^{1}$ \\ ${ }^{1}$ Nature Research Centre, Akademijos, Vilnius, Lithuania; \\ ${ }^{2}$ Vytautas Magnus University, Faculty of Natural Sciences, Department of Biology, Kaunas, Lithuania
}

\begin{abstract}
A morphological type of Sarcocystis cysts found in one of two examined great black-backed gull, Larus marinus (Linnaeus) (Laridae), is considered to represent a new species for which the name Sarcocystis lari sp. n. is proposed and its description is provided. The cysts are ribbon-shaped, very long (the largest fragment found was $6 \mathrm{~mm}$ long) and relatively narrow (up to $75 \mu \mathrm{m}$ ). Under a light microscope the cyst wall reaches up to $1 \mu \mathrm{m}$ and seems to be smooth. Using a computerized image analysis system, knolls, which resemble protrusions on the wall surface, are visible. Lancet-shaped cystozoites measure in average $6.9 \times 1.4 \mu \mathrm{m}$ (range 6.3-7.9 $\mu \mathrm{m} \times 1.2-1.5 \mu \mathrm{m}$ ) in length. Observed using Transmission electron microscopy (TEM), the cyst wall is wavy and measures up to $1.2 \mu \mathrm{m}$ in thickness. The parasitophorous vacuolar membrane has regularly arranged small invaginations. Cyst content is divided into large chambers by septa. Sarcocystis lari sp. n. has type-1 tissue cyst wall and is morphologically indistinguishable from other bird Sarcocystis species characterized by the same type of the wall. On the basis of 18S rRNA gene, 28S rRNA gene and ITS-1 region sequences, $S$. lari is a genetically distinct species, being most closely related to avian Sarcocystis species whose definitive hosts are predatory birds.
\end{abstract}

Keywords: Heteroxenous coccidia, new species, taxonomy, electron microscopy, 18S rDNA, 28S rDNA, ITS-1, phylogeny

Representatives of the genus Sarcocystis Lankester, 1892 are cyst-forming coccidians, parasites of mammals, birds and reptiles, and are characterized by an obligatory prey-predator two-host life cycle (Mehlhorn and Heydorn 1978). Asexual multiplication occurs in intermediate hosts and following merogony sarcocysts are formed in the muscle tissues. The sexual phase with formation of oocysts/sporocysts takes place in the small intestine of the definitive host (Dubey et al. 1989).

Until now, far over 30 named Sarcocystis species whose intermediate hosts are birds have been described (Kutkienè et al. 2012a). Some avian Sarcocystis species, i.e. S. falcatula Stiles, 1893 and S. calchasi Olias, Grubber, Hafez, Hafez, Heydorn, Mehlhorn et Lierz, 2010 are pathogenic for their hosts (Smith et al. 1990, Olias et al. 2010a), including S. neurona Dubey, Davis, Speer, Bowman, de Lahunta, Granstrom, Topper, Hamir, Cummings et Suter, 1991, which parasitizes taxonomically distant mammal species, in which infects central nervous system, and was also identified in the brown headed cowbird, Molothrus ater (Boddaert) (Mansfield et al. 2008).

There are only a few reports about Sarcocystis spp. parasitizing gulls (Laridae). Pak and Eshtokina (1984) found cysts of Sarcocystis sp. in the common black-headed gull, Larus ridibundus (Linnaeus), and in the mew gull, Larus canus (Linnaeus), in Kazakhstan. In both bird species the sarcocysts found had thin and smooth cyst wall and small banana-shaped cystozoites. In Canada, microcysts with a thin wall and a smooth outer surface were detected in the California gull, Larus californicus (Lawrence) (Drouin and Mahrt 1980). Prakas et al. (2011a) also found thin-walled sarcocysts in the herring gull, Larus argentatus (Pontoppidan) in Lithuania. On the basis of a comparative analysis of morphological data obtained by light and electron microscopy in combination with DNA data, Sarcocystis sp. from the herring gull was identified as S. wobeseri-like.

In the present paper, a new species of Sarcocystis is described from the great black-backed gull, Larus marinus (Linnaeus), based on morphological and molecular data.

\section{MATERIALS AND METHODS}

Samples collection and processing for light microscopy

Two great black-backed gulls, found dead in Šilute district of Lithuania on 18 September 2011, were examined. Neck and leg muscles of both birds were investigated for the pres- 
Table 1. List of taxa analysed and GenBank accession number of their sequences used in the phylogenetic analysis; sequences obtained in the present study are in bold.

\begin{tabular}{|c|c|c|c|}
\hline \multirow[t]{2}{*}{ Taxon name } & \multicolumn{3}{|c|}{ Accession no. and sequence length (bp) } \\
\hline & $18 \mathrm{~S}$ rDNA & 28S rDNA & ITS-1 \\
\hline Besnoitia besnoiti (outgroup) & AF109678 (1797) & AF076900 (3221) & \\
\hline Frenkelia glareoli & AF009245 (1630) & AF044251 (3286) & \\
\hline Frenkelia microti & AF009244 (1631) & AF044252 (3283) & \\
\hline Sarcocystis albifronsi & EU502868 (1792) & EF079885 (1409) & JF520780 (939) \\
\hline Sarcocystis anasi & EU553477 (1792) & EF079887 (1446) & JF520779 (941) \\
\hline Sarcocystis arieticanis & L24382 (1821) & AF076904 (3500) & \\
\hline Sarcocystis calchasi & GQ245670 (1804) & FJ232949 (3288) & FJ232948 (838) \\
\hline Sarcocystis canis & & & DQ176645 (1116) \\
\hline Sarcocystis capracanis & L76472 (1839) & AF012885 (3461) & \\
\hline Sarcocystis columbae & GU253883 (1630) & GU253887 (1460) & GU253885 (833) \\
\hline Sarcocystis cornixi & EU553478 (1795) & EF079884 (1445) & JF520781 (876) \\
\hline Sarcocystis corvusi & JN256117 (1792) & JN256118 (1413) & JN256119 (838) \\
\hline Sarcocystis cruzi & AF017120 (1818) & AF076903 (3454) & \\
\hline Sarcocystis falcatula & & & AY082638 (1021) \\
\hline Sarcocystis felis & & & AY190081 (865) \\
\hline Sarcocystis gallotiae & AY015112 (1591) & AF513494 (468) & \\
\hline Sarcocystis gigantea & L24384 (1830) & U85706 (3475) & \\
\hline Sarcocystis kalvikus & & & GU200661 (896) \\
\hline Sarcocystis lacertae & AY015113 (1802) & AF513495 (475) & \\
\hline Sarcocystis lari sp. $\mathbf{n}$. & JQ733508 (1802) & JQ733509 (1434) & JQ733510 (860) \\
\hline Sarcocystis lindsayi & & & AF387164 (1197) \\
\hline Sarcocystis moulei & L76473 (1851) & AF012884 (3497) & \\
\hline Sarcocystis muris & M64244 (1809) & AF012883 (3295) & \\
\hline Sarcocystis neurona & U07812 (1803) & AF092927 (3281) & AY009113 (1053) \\
\hline Sarcocystis rileyi & GU120092 (1643) & GU188426 (3196) & GU188427 (1079) \\
\hline Sarcocystis rodentifelis & AY015111 (1593) & AF513496 (577) & \\
\hline Sarcocystis singaporensis & AF434054 (1801) & AF237617 (3431) & \\
\hline Sarcocystis tarandi (outgroup) & & & GQ250962 (641) \\
\hline Sarcocystis tenella & L24383 (1782) & AF076899 (3461) & \\
\hline Sarcocystis turdusi & JF975681 (1793) & JF975682 (1469) & JF975683 (802) \\
\hline Sarcocystis wobeseri & GQ922885 (1792) & GQ922887 (1507) & GU475111 (844) \\
\hline Sarcocystis sp. ex Diplothrix legata & AB691780 (1797) & AB691781 (1441) & \\
\hline Sarcocystis sp. ex Morus bassanus & & & AY082640 (1022) \\
\hline Sarcocystis sp. ex Mus musculus & AF513490 (1635) & AF513493 (638) & \\
\hline Sarcocystis sp. ex Physeter macrocephalus & & & HQ184185 (800) \\
\hline Sarcocystis sp. ex Psittacus erithacus & & & DQ768306 (779) \\
\hline Sarcocystis sp. ex Sorex araneus & AF513487 (1594) & AF513497 (554) & \\
\hline
\end{tabular}

ence of Sarcocystis cysts. For this purpose, 28 oat-size pieces (ca $1 \mathrm{~g})$ of muscles were cut-off, stained with water $(1: 500)$ methylene blue solution, clarified with $1.5 \%$ acetic acid solution and pressed in a glass compressor. Infection intensity was determined by counting sarcocysts in 28 sections of the muscles examined.

\section{Light microscopy}

The sarcocyst size and shape, structure of cyst walls and morphometric parameters of cystozoites were evaluated using the computerized image analysis system Infinity 3 . The morphometric analysis of cysts and cystozoites was performed in fresh preparations after the cysts had been isolated from muscle fibres with two preparation needles.

\section{Transmission electron microscopy (TEM)}

For TEM a small piece of muscles containing one mature cyst of Sarcocystis was fixed in Karnovsky's fixative, postfixed in $1 \%$ osmium tetroxide, dehydrated and embedded in Epon. Ultrathin sections were stained with $2 \%$ uranyl acetate and lead citrate and examined under the JEOL JEM-100B TEM.

\section{Molecular analysis}

Genomic DNA was extracted from a few mature sarcocysts, which were isolated from one black-backed gull using the $\mathrm{Nu}$ cleoSpin Tissue kit (Macherey-Nagel, Düren, Germany). Partial 28S rRNA gene sequence containing D2 and D3 domains, fulllength 18S rRNA gene and ITS-1 region were amplified using seven primer pairs KL-P1F\KL-P1R, KL-P2F $\backslash K L-P 2 R$, SarAF $\backslash$ SarAR, SarBF \SarBR, SarCF \SarCR, SarDF $\backslash$ SarDR, P-ITSF $\backslash P$ ITSR (Kutkienė et al. 2010).

PCRs were performed in the final $25 \mu 1$ volume consisting of $1 \times$ PCR buffer (with $50 \mathrm{mM} \mathrm{KCl}$ ), $0.2 \mathrm{mM}$ dNTP, $0.2 \mu \mathrm{M}$ of each primer, $2.5 \mathrm{mM} \mathrm{MgCl}_{2}, 1 \mathrm{U}$ Taq DNA polymerase (MBI Fermentas, Vilnius, Lithuania) and $0.04 \mu \mathrm{g}$ template DNA. Amplification reactions were carried out with initial denaturing step at $95^{\circ} \mathrm{C}$ for $5 \mathrm{~min}, 5$ cycles at $94^{\circ} \mathrm{C}$ for $45 \mathrm{~s}$, at $64^{\circ} \mathrm{C}$ for $60 \mathrm{~s}$, at $72^{\circ} \mathrm{C}$ for $70 \mathrm{~s}$, followed by 30 cycles at $94^{\circ} \mathrm{C}$ for $45 \mathrm{~s}$, at $58^{\circ} \mathrm{C}$ for $60 \mathrm{~s}$, at $72^{\circ} \mathrm{C}$ for $70 \mathrm{~s}$ and ended with the final extension at $72^{\circ} \mathrm{C}$ for $10 \mathrm{~min}$. The PCR products were visualized using $1.7 \%$ agarose gel electrophoresis and purified with the help of exonu- 

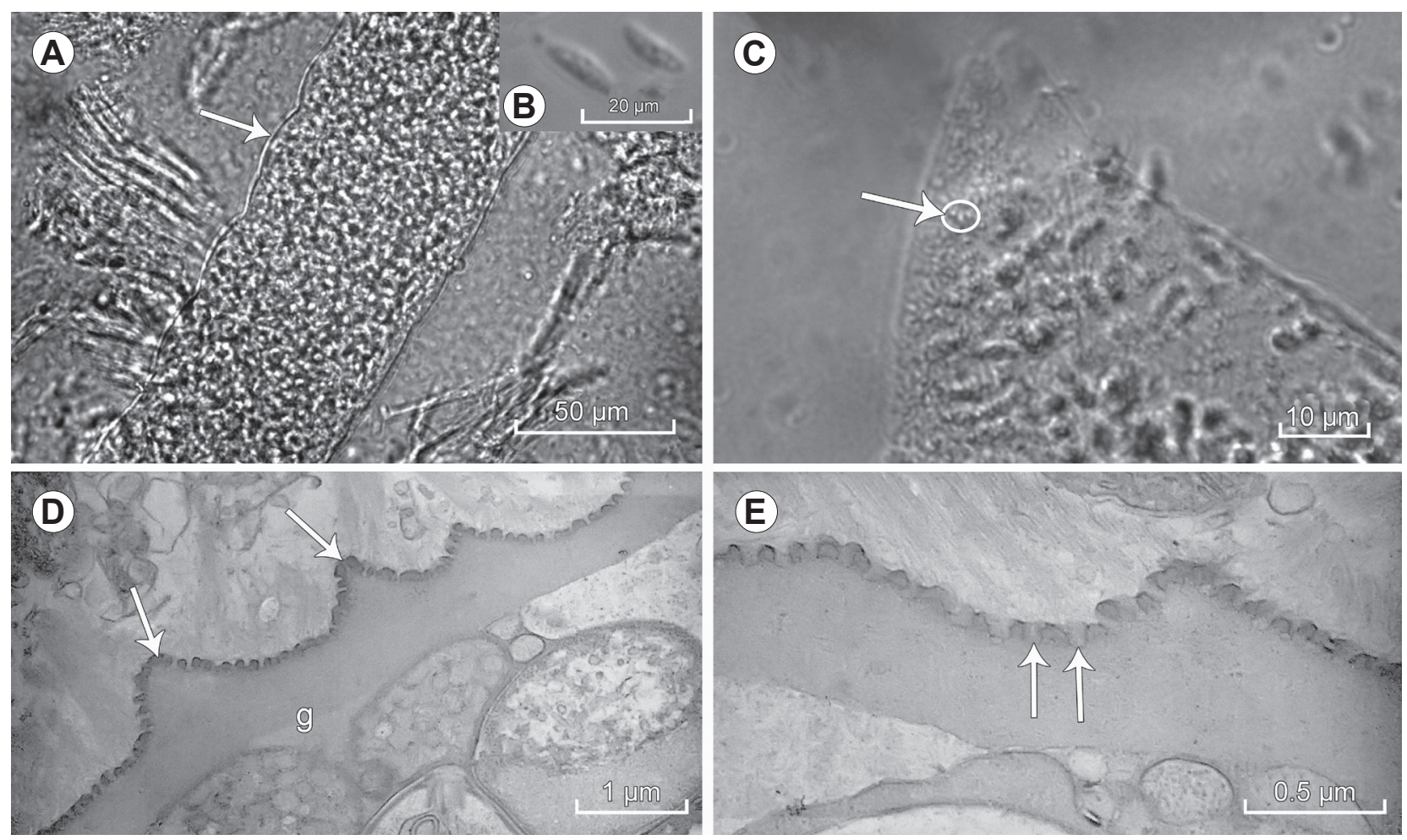

Fig. 1. Sarcocystis lari sp. n. from the leg muscles of the great black-backed gull, Larus marinus. A-C - light micrographs. Fresh preparations. A - fragment of the cyst: arrow pointed at the thin cyst wall. B - lancet-shaped cystozoites. $\mathbf{C}$ - fragment of the cyst: note knolls on the surface of the cyst wall, resembling protrusions (arrow). D, $\mathbf{E}-$ transmission electron micrographs. D - wavy sarcocyst wall: arrows pointed at 'waves' that resemble protrusions of different height; g - ground substance (arrows). E - higher magnification of the cyst wall; the membrane of parasitophorous vacuolar with regularly arranged small invaginations (arrows pointed at invaginations).

cleases ExoI and FastAP. PCR products were sequenced with 3130xl Genetic Analyzer using the same forward and reverse primers as for PCR.

The pairwise distances between sequences were calculated with MEGA5 (Tamura et al. 2011). Analyses were conducted using the maximum composite likelihood model and all positions containing gaps were eliminated (Tamura et al. 2004). Sequences were aligned using the MUSCLE algorithm (Edgar 2004). The beginning and the end of some sequences were truncated to have all sequences beginning and ending in the same nucleotide positions. The final alignment based on concatenated partial the 18S rRNA and the 28S rRNA gene sequences contained 28 taxa and 2394 nucleotide positions, from which 1764 belonged to $18 \mathrm{~S}$ rRNA gene and 630 belonged to $28 \mathrm{~S}$ rRNA gene. In addition, 20 taxa and 1162 nucleotide positions made alignment of ITS-1 sequences.

Taxon names and GenBank accession numbers of all sequences included in the phylogenetic analysis are presented in Table 1. Sarcosystis tarandi Gjerde, 1984 and Besnoitia besnoiti Marotel, 1912 were set as outgroups of ITS-1 phylogenetic tree and $18 \mathrm{~S}$ rRNA/28S rRNA genes phylogenetic tree, respectively. Phylogenetic relationships were assessed using Bayesian inference with the MrBayes program, version 3.1.2 (Ronquist and Huelsenbeck 2003). The most complex evolutionary model available, i.e. GTR + I + G model, was chosen for the phylogenetic analysis.

\section{RESULTS}

Sarcocystis lari sp. n.

Fig. 1

Morphological description (measurements are provided in micrometers unless otherwise stated). Sarcocysts ribbon-shaped, long (largest fragment $6 \mathrm{~mm}$ in length), relatively narrow (up to 75). Under light microscope, cyst wall reached up to 1 in thickness, appearing smooth (Fig. 1A). Using computerized image analysis system, knolls resembling protrusions clearly visible on wall surface (Fig. 1C). Lancet-shaped cystozoites $6.9 \times$ $1.4(6.3-7.9 \times 1.2-1.5)$ in size $(n=10)$ (Fig. 1B). Under transmission electron microscope (TEM), cyst wall wavy, measuring up to 1.2 in thickness (Fig. 1D). Waves of different height; in some places cyst wall seemingly almost smooth. Parasitophorous vacuolar membrane with regularly arranged small invaginations (Fig. 1E). Cyst content divided into large chambers by septa. Cyst wall of type-1 (see Dubey et al. 1989 for terminology).

Sarcocystis cysts were detected in one of two great black-backed gulls examined. Sixteen and 39 sarcocysts were found in 28 sections of neck and leg muscles, respectively. All cysts were mature. Only one morphological type of sarcocysts was found and proposed as a new Sarcocystis species. 
Table 2. Pairwise distances (p-distance) of the 18S rRNA gene, 28S rRNA gene and ITS-1 region sequences of Sarcocystis species from birds.

\begin{tabular}{|c|c|c|c|c|c|c|c|c|c|c|c|}
\hline & & 1 & 2 & 3 & 4 & 5 & 6 & 7 & 8 & 9 & 10 \\
\hline 1 & S. albifronsi & $* * *$ & 0.1166 & 0.8493 & 0.9583 & 0.9704 & 0.9222 & 0.9451 & 0.4386 & 0.8924 & 0.8442 \\
\hline 2 & S. anasi & $\begin{array}{c}0.0025 / \\
0.0073\end{array}$ & $* * *$ & 0.8927 & 0.9644 & 0.9778 & 0.9178 & 0.9777 & 0.4713 & 0.8777 & 0.8736 \\
\hline 3 & S. calchasi & $\begin{array}{c}0.0059 / \\
0.0351\end{array}$ & $\begin{array}{l}0.0050 / \\
0.0359\end{array}$ & $* * *$ & 0.1994 & 0.1841 & 0.2157 & 0.2687 & 0.9567 & 0.1897 & 0.0554 \\
\hline 4 & S. columbae & $\begin{array}{c}0.0063 / \\
0.0391\end{array}$ & $\begin{array}{c}0.0055 / \\
0.0390\end{array}$ & $\begin{array}{l}0.0004 / \\
0.0095\end{array}$ & $* * *$ & 0.2219 & 0.0633 & 0.3580 & 0.9940 & 0.2368 & 0.1870 \\
\hline 5 & S. cornixi & $\begin{array}{c}0.0076 / \\
0.0401\end{array}$ & $\begin{array}{c}0.0068 / \\
0.0400\end{array}$ & $\begin{array}{c}0.0029 / \\
0.0110\end{array}$ & $\begin{array}{c}0.0033 / \\
0.0103\end{array}$ & $* * *$ & 0.2175 & 0.2990 & 1.0237 & 0.1306 & 0.1735 \\
\hline 6 & S. corvusi & $\begin{array}{c}0.0063 / \\
0.0399\end{array}$ & $\begin{array}{c}0.0055 / \\
0.0398\end{array}$ & $\begin{array}{c}0.0004 / \\
0.0088\end{array}$ & $\begin{array}{c}0.0008 / \\
0.0022\end{array}$ & $\begin{array}{c}0.0033 / \\
0.0110\end{array}$ & $* * *$ & 0.3596 & 1.0093 & 0.2360 & 0.2003 \\
\hline 7 & S. lari sp. n. & $\begin{array}{c}0.0055 / \\
0.0375\end{array}$ & $\begin{array}{c}0.0046 / \\
0.0366\end{array}$ & $\begin{array}{c}0.0021 / \\
0.0132\end{array}$ & $\begin{array}{c}0.0025 / \\
0.0155\end{array}$ & $\begin{array}{c}0.0033 / \\
0.0133\end{array}$ & $\begin{array}{c}0.0025 / \\
0.0148\end{array}$ & $* * *$ & 1.0071 & 0.2923 & 0.2304 \\
\hline 8 & S. rileyi & $\begin{array}{c}0.0038 / \\
0.0301\end{array}$ & $\begin{array}{c}0.0038 / \\
0.0301\end{array}$ & $\begin{array}{c}0.0046 / \\
0.0417\end{array}$ & $\begin{array}{c}0.0050 / \\
0.0408\end{array}$ & $\begin{array}{c}0.0067 / \\
0.0433\end{array}$ & $\begin{array}{c}0.0050 / \\
0.0416\end{array}$ & $\begin{array}{c}0.0042 / \\
0.0441\end{array}$ & $* * *$ & 0.9747 & 0.9795 \\
\hline 9 & S. turdusi & $\begin{array}{c}0.0063 / \\
0.0384\end{array}$ & $\begin{array}{c}0.0055 / \\
0.0383\end{array}$ & $\begin{array}{l}0.0012 / \\
0.0103\end{array}$ & $\begin{array}{c}0.0017 / \\
0.0088\end{array}$ & $\begin{array}{c}0.0025 / \\
0.0066\end{array}$ & $\begin{array}{c}0.0017 / \\
0.0095\end{array}$ & $\begin{array}{l}0.0017 / \\
0.0125\end{array}$ & $\begin{array}{l}0.0050 / \\
0.0408\end{array}$ & $* * *$ & 0.1790 \\
\hline 10 & S. wobeseri & $\begin{array}{c}0.0059 / \\
0.0359\end{array}$ & $\begin{array}{c}0.0050 / \\
0.0359\end{array}$ & $\begin{array}{c}0.0000 / \\
0.0058\end{array}$ & $\begin{array}{c}0.0004 / \\
0.0066\end{array}$ & $\begin{array}{c}0.0029 / \\
0.0080\end{array}$ & $\begin{array}{c}0.0004 / \\
0.0058\end{array}$ & $\begin{array}{c}0.0021 / \\
0.0118\end{array}$ & $\begin{array}{c}0.0046 / \\
0.0417\end{array}$ & $\begin{array}{c}0.0012 / \\
0.0088\end{array}$ & $* * *$ \\
\hline
\end{tabular}

Pairwise distances of ITS-1 region are shown above the diagonal, pairwise distances of 18S rRNA gene and 28S rRNA gene, respectively, below diagonal.

Molecular analysis. When comparing Sarcocystis species whose intermediate hosts are birds, the highest sequence variation was observed within ITS-1 region. Fluctuations of $\mathrm{p}$-distance values within the $18 \mathrm{~S}$ rRNA gene, 28S rRNA gene and ITS-1 region of the analysed Sarcocystis species from birds were 0-0.0076, $0.0022-0.0441$ and $0.0554-1.0237$, respectively (Table 2). According to three DNA markers, S. lari had the lowest p-distance values when compared to $S$. turdusi Kutkienè, Prakas, Butkauskas et Sruoga, 2012 from the blackbird and to $S$. wobeseri Kutkiene, Prakas, Sruoga et Butkauskas, 2010, whose intermediate hosts are the barnacle goose and mallard (0.0017 and 0.0021 within the $18 \mathrm{~S}$ rRNA gene; 0.0125 and 0.0118 within the $28 \mathrm{~S}$ rRNA gene; 0.2923 and 0.2304 within ITS- 1 region). Relatively high sequences identity of the ITS-1 region was observed between S. lari and S. canis Dubey et Speer, 1991, S. felis Dubey, Hamir, Kirkpatrick, Todd et Rupprecht, 1992 and S. kalvikus Dubey, Reichard, Torretti, Garvon, Sundar et Grigg, 2010, whose intermediate hosts are predatory mammals, with p-distance values varying from 0.2821 to 0.3458 . In conclusion, the DNA sequence analysis shows that $S$. lari is a genetically distinct species.

Inside the phylogenetic tree of the concatenated sequences of $18 \mathrm{~S}$ rRNA and 28S rRNA genes, several well-supported clades could be distinguished (Fig. 2). Sarcocystis gallotiae Matuschka et Mehlhorn, 1984 and S. lacertae Babudieri, 1932, characterized by a life cycle with reptiles serving both as intermediate and definitive hosts, composed clade A. Sarcocystis species forming sarcocysts in even-toed ungulates were united into group B, which was divided into two subgroups that included Sarcocystis species transmitted through canines or felines.
Other Sarcocystis species, whose intermediate hosts were rodents, were placed into $\mathrm{C}$ and $\mathrm{E}$ clades, whereas Sarcocystis sp. from the Ryukyu long-tailed giant rat, Diplothrix legata (Thomas), was placed separately. Definitive hosts of Sarcocystis species from the group C were reptiles and definitive hosts of the group E species were felids. Likewise, Sarcocystis species forming sarcocysts in birds were divided into clade D and F. Predatory birds are definitive hosts of the Sarcocystis species of the group $\mathrm{D}$ and predatory mammals of species of the group F. Sarcocystis neurona, which is typical by parasitism in taxonomically distant intermediate hosts, formed a separate branch in the phylogram.

Sarcocystis lari was grouped together with Sarcocystis species from birds, Sarcocystis sp. from the common shrew, Sorex araneus (Linnaeus), and members of the genus Frenkelia Biocca, 1968 in the $18 \mathrm{~S}$ rRNA/28S rRNA genes phylogenetic tree. On the basis of the ITS-1 region phylogenetic tree, $S$. lari was most closely related to $S$. calchasi, S. wobeseri, S. columbae Olias, Olias, Lierz, Mehlhorn et Grubber, 2010, S. corvusi Prakas, Kutkienè, Butkauskas, Sruoga et Žalakevičius, 2013, S. cornixi Kutkienè, Prakas, Sruoga et Butkauskas, 2009 and S. turdusi, all parasitizing birds (Fig. 3). Interestingly, these species were phylogenetically close to Sarcocystis spp. forming sarcocysts in predatory mammals. In the phylogram of ITS-1 sequences, other Sarcocystis species, whose intermediate hosts are birds, grouped with $S$. neurona.

Type and intermediate host: Larus marinus (Linnaeus) (Charadriiformes: Laridae).

Definitive host: Unknown.

Type locality: Šilute district (near the Baltic Sea), west-

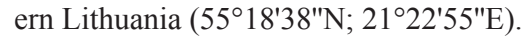




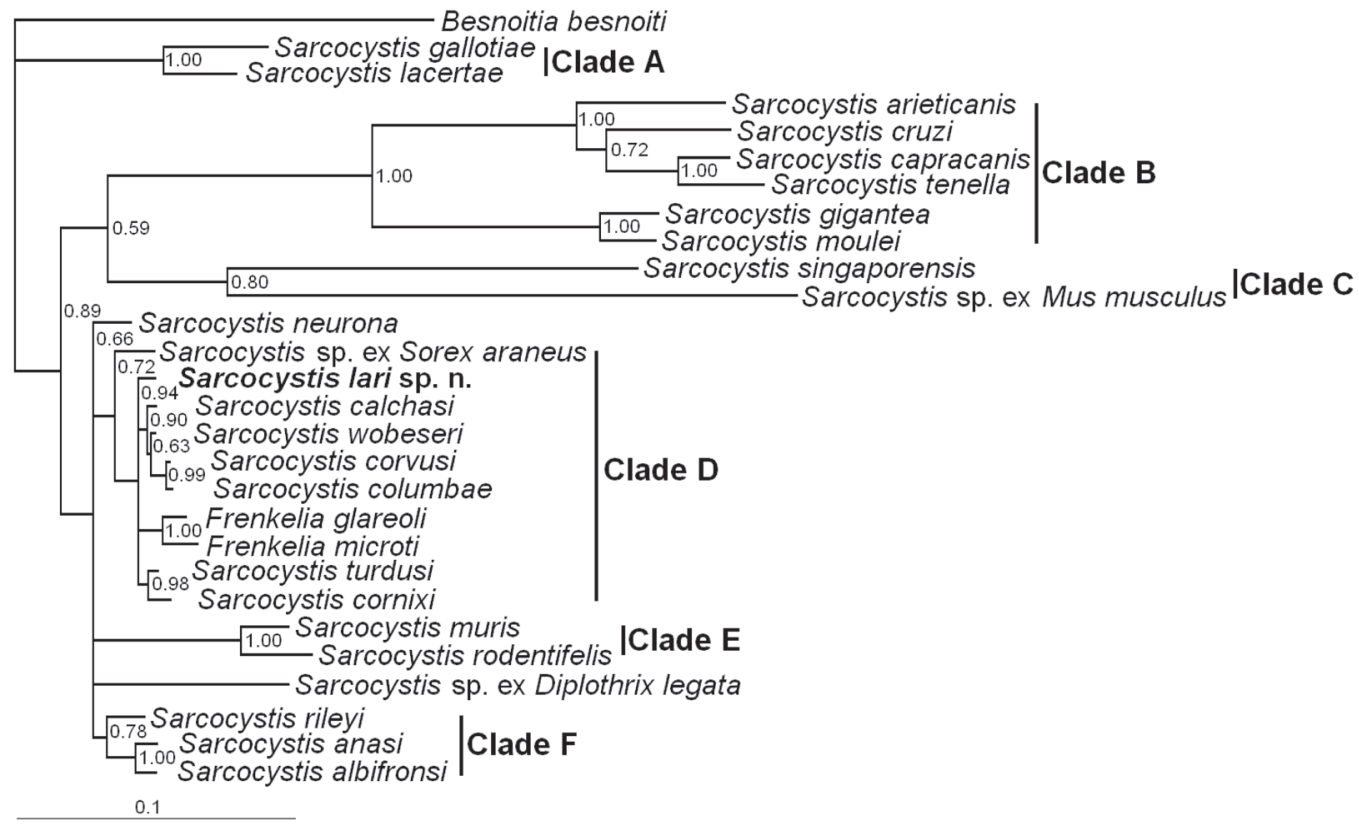

Fig. 2. The phylogram of species of genus Sarcocystis based on concatenated sequences of $18 \mathrm{~S}$ rRNA and $28 \mathrm{~S}$ rRNA genes. The tree was constructed using the Bayesian method, rooted with Besnoitia besnoiti as outgroup and scaled according to the branch length. The numbers in the figure indicate the posterior probability support values. Six major clades A-F were distinguished in the phylogram (see the text).

GenBank accession numbers: JQ733508 (18S rRNA gene), JQ733509 (28S rRNA gene), JQ733510 (ITS-1 region).

Specimens deposited: TEM material and DNA samples are deposited at the Institute of Ecology, Nature Research Centre, Vilnius, Lithuania; not accessioned.

Etymology: Species name is derived from the genitive of the generic name of type host.

\section{DISCUSSION}

Cyst morphology is one of the main criteria for characterizing a new Sarcocystis species or for identifying the already known species (Dubey et al. 1989). Morphological parameters are usually described using a light microscope, which may be connected to a computerized image analysis system, transmission electron microscope (TEM) and scanning electron microscope (SEM). Each of these devices used alone does not give a full picture of the morphology of the sarcocysts analysed. Thus far morphological data obtained mainly by light microscopy and TEM have been used to describe new Sarcocystis species. However, a full view of the cyst surface, which is a very important feature for the characterization of the morphology of the cyst, is not obtained using light microscopy or the TEM analysis. SEM, with the help of which the full view of the cyst surface is obtained, can be partly replaced with light microscopy with the computerised image analysis system. In this case, when changing lightening and optical levels in different ways, the structure of the cyst wall becomes much better visible than when using light microscopy alone.
Dubey and Odening (2001) categorized sarcocyst walls into 37 types, which is significant for diagnostics of the species. Morphology of all cyst wall types has been described using TEM. Moreover, it was stated that the same cyst wall type can be detected in Sarcocystis species parasitizing different taxonomic groups of animals. The most primitive cyst wall type- 1 is characterized as "the basic type in which the cyst wall is devoid of any villar protrusions; its surface is provided with arranged small invaginations and can be undulated ( $S$. muris (Railliet, 1886) Labbé, 1899) (Dubey et al. 1989). The view of the cyst wall obtained by TEM does not make it possible to understand why the cyst wall of this type seems wavy.

In the present work and in our earlier investigations (Kutkienè et al. 2010, Prakas et al. 2011a, 2013), using the computerized image analysis system we discovered that cysts of Sarcocystis with cyst wall type-1 had knolls on the wall surface, which resembled protrusions. They are also clearly visible on the cyst wall surface of $S$. lari, because most of the cystozoites are spilled out from the cut of the cyst made during observation. Therefore, cystozoites do not form a dark background and do not prevent viewing the cyst wall surface (Fig. 1C). Knolls are not resistant to a mechanical effect, i.e. when coverslip is pressed strongly they become more flattened. Undulations of the cyst wall in electron micrographs depend on the place where a cyst is cut; the cyst wall seems almost smooth if the cyst is cut between the knolls. Hence, it can be concluded that the surface of the cyst wall type1 discovered in birds is not smooth but has clearly vis- 


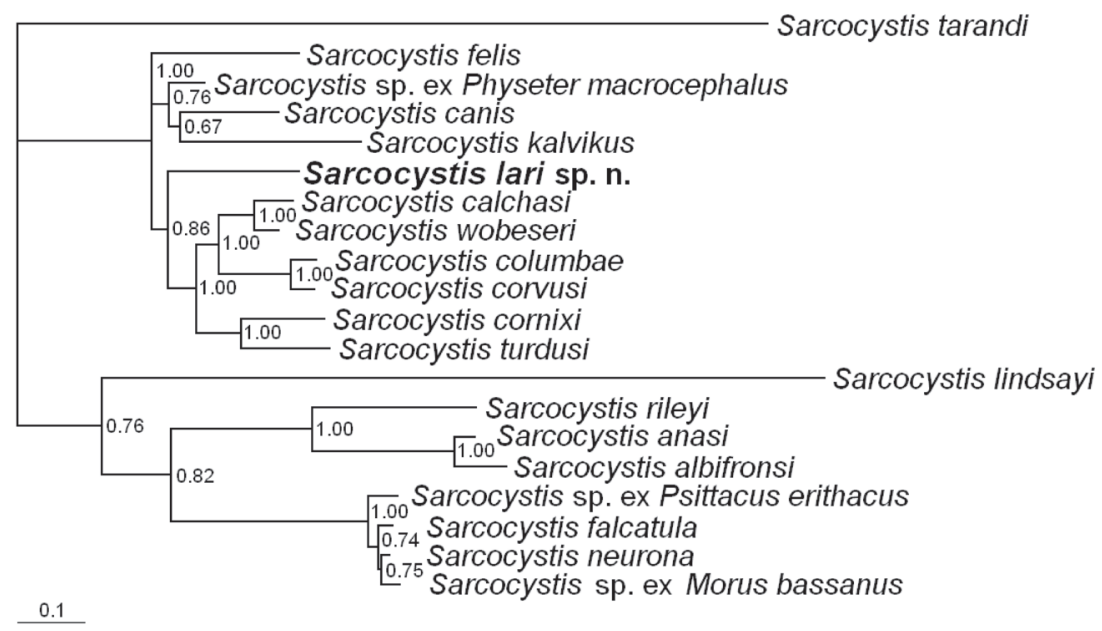

Fig. 3. The phylogram of species of genus Sarcocystis based on sequences of ITS-1 region. The tree was constructed using the Bayesian methods, rooted on Sarcocystis tarandi and scaled according to the branch length. The numbers in the figure indicate the posterior probability support values.

ible knolls, which resemble protrusions. It is very likely that cysts with cyst wall type-1 found in other taxonomic groups of animals have similar formations on the wall surface.

In this work the morphological parameters of the cyst of the newly described S. lari from the great black-backed gull obtained by light microscopy were similar to those of sarcocysts discovered in the California gull (Drouin and Mahrt 1980), the black-headed gull and the mew gull (Pak and Eshtokina 1984). Unfortunately, ultrastructural studies of sarcocysts isolated from the mentioned birds were not carried out; therefore, a more detailed comparison of these species is impossible. When studied under a light microscope, $S$. wobeseri-like sarcosporidia from the herring gull (Prakas et al. 2011a) and S. lari did not differ from each other in taxonomically important morphological characteristics. Sequences of the $18 \mathrm{~S}$ rRNA and $28 \mathrm{~S}$ rRNA gene and ITS-1 region of $S$. wobeseri-like coccidia did not differ significantly from those of $S$. wobeseri, whereas differ significantly from those of $S$. lari.

Cyst wall type-1 has been found in the following species of Sarcocystis parasitizing birds: S. corvusi from the Eurasian jackdaw, Corvus monedula (Linnaeus), $S$. wobeseri from the barnacle goose, Branta leucopsis (Bechstein), and Sarcocystis sp. from the common goldeneye, Bucephala clangula (Linnaeus) (Kutkienè et al. 2008, 2010, Prakas et al. 2013). According to the published electron micrographs, the same cyst wall type-1 is present also in S. calchasi from the rock dove, Columba livia f. domestica (Gmelin), S. columbae from the common woodpigeon, Columba palumbus (Linnaeus), and Sarcocystis spp. from the white-rumped swift, Apus caffer (Lichtenstein), black-crowned night-heron, Nycticorax nycticorax (Linnaeus) and snow goose, Anser caerulescens caerulescens (Linnaeus) (Kaiser and Markus 1983, Olias et al. 2010b,c, Wobeser et al. 1981).
Thus, the same morphological cyst wall type is found not only in larids but also in unrelated species of birds. Sarcocystis calchasi, S. columbae, S. corvusi and $S$. wobeseri were identified mainly on the basis of DNA sequences (Kutkienè et al. 2010, Olias et al. 2010a,c, Prakas et al. 2013). It should be noted that molecular data inferred from the 18S rRNA and 28S rRNA gene sequences were insufficient to separate these phylogenetically closely related and evolutionary relatively young Sarcocystis species from birds. Therefore, the more rapidly evolving ITS-1 region was used to distinguish these species (Prakas et al. 2013).

The scenario of co-evolution of Sarcocystis spp. forming sarcocysts in mammals, reptiles and birds with their final hosts rather than with the intermediate ones was already suggested in earlier phylogenetic studies (Jeffries et al. 1997, Doležel et al. 1999, Prakas et al. 2011b). The results of the present work support this assumption. It should be noted, however, that definitive hosts are not known for all Sarcocystis species that have been included in phylogenetic analyses. In the phylogenetic tree based on concatenated sequences of the $18 \mathrm{~S}$ rRNA and $28 \mathrm{~S}$ rRNA genes, $S$. lari appears inside the clade D (Fig. 2) together with Sarcocystis species whose definitive hosts are birds. In the phylogram based on ITS-1 sequences, S. lari forms a clade with six Sarcocystis spp. from birds. Sarcocysts of $S$. lari have a type-1 tissue cyst wall, similarly as those of $S$. calchasi, S. columbae, S. corvusi and $S$. wobeseri. However, according to the phylogram inferred from ITS-1 sequences, $S$. calchasi, $S$. columbae, $S$. corvusi and $S$. wobeseri were more closely related to S. cornixi and S. turdusi than to $S$. lari.

This pattern of phylogenetic relationship might be explained by the characteristics of life cycles of the species compared. Definitive hosts of $S$. calchasi, S. columbae and $S$. turdusi are most likely predatory birds of the genus 
Accipiter Brisson (see Olias et al. 2011, Kutkienė et al. $2012 \mathrm{~b}$ ). The intermediate host of $S$. lari, the great blackbacked gull, is the largest gull species and main natural predators of these adult birds are the golden eagle, Aquila chrysaetos (Linnaeus), bald eagle, Haliaeetus leucocephalus (Linnaeus) and the white-tailed sea-eagle, Haliaeetus albicilla (Linnaeus) (see Good 1998).
Acknowledgements. The authors express their gratitude to Mrs. I. Žalakevičiene from the Centre of Innovative Medicine, Department of Experimental and Clinical Medicine (Vilnius, Lithuania) for her help in carrying out electron microscopical investigations.

\section{REFERENCES}

Doležel D., Koudela B., JirkŮ M., Hypša V., Oborník M., VotýpKa J., Modrý D., Šlapeta J.R., Lukeš J. 1999: Phylogenetic analysis of Sarcocystis spp. of mammals and reptiles supports the coevolution of Sarcocystis spp. with their final hosts. Int. J. Parasitol. 29: 795-798.

Drouin T.E., Mahrt J.L. 1980: The morphology of cysts of Sarcocystis infecting birds in western Canada. Can. J. Zool. 58: $1477-1482$.

Dubey J.P., Odening K. 2001: Toxoplasmosis and related infections. In: W.M. Samuel, M.J. Pybus and A.A.Kocan (Eds.), Parasitic Diseases of Wild Mammals. Iowa State University Press, Ames, Iowa, pp. 478-519.

Dubey J.P., Speer C.A., Fayer R. 1989: Sarcocystosis of Animals and Man. CRC Press, Boca Raton, Florida, 215 pp.

EDGAR R.C. 2004: MUSCLE: multiple sequence alignment with high accuracy and high throughput. Nucl. Acids Res. 32: 17921797.

Good T.P. 1998: Great black-backed gull (Larus marinus). In: A. Poole and F. Gill (Eds.), The Birds of North America. The Birds of North America, Inc., Pennsylvania, pp. 1-32.

Jeffries A.C., Schnitzler B., Heydorn A.O., Johnson A.M., Tenter A.M. 1997: Identification of synapomorphic characters in the genus Sarcocystis based on $18 \mathrm{~S}$ rDNA sequences comparison. J. Euk. Microbiol. 44: 388-392.

Kaiser I.A., Markus M.B. 1983: Species of Sarcocystis in wild South African birds. Proc. Electron. Microscop. Soc. S. Afr. 13: 103-104.

Kutkiené L., Prakas P., Butkauskas D., Sruoga A. 2012b: Description of Sarcocystis turdusi sp. nov. from the common blackbird (Turdus merula). Parasitology 139: 1438-1443.

Kutkienè L., Prakas P., Sruoga A., Butkauskas D. 2010: The mallard duck (Anas platyrhynchos) as intermediate host for Sarcocystis wobeseri sp. nov. from the barnacle goose (Branta leucopsis). Parasitol. Res. 107: 879-888.

Kutkiené L., Prakas P., Sruoga A., Butkauskas D. 2012a: Description of Sarcocystis anasi sp. nov. and Sarcocystis albifronsi sp. nov. in birds of the oder Anseriformes. Parasitol. Res. 110: $1043-1046$.

Kutkiené L., Sruoga A., Butkauskas D. 2008: Sarcocystis sp. from the goldeneye (Bucephala clangula) and the mallard (Anas platyrhynchos): cyst morphology and ribosomal DNA analysis. Parasitol. Res. 102: 691-696.

Mansfield L.S., Mehler S., Nelson K., Elsheikha H.M., Murphy A.J., Knust B., Tanhauser S.M., Gearhart P.M., Rossano M.G., Bowman D.D., Schott H.C., Patterson J.S. 2008: Brown-headed cowbirds (Molothrus ater) harbour Sarcocystis neurona and act as intermediate hosts. Vet. Parasitol. 153: $24-43$.

Received 2 January 2013
Mehlhorn H., Heydorn A. O. 1978: The Sarcosporidia (Protozoa, Sporozoa): life cycle and fine structure. Adv. Parasitol. 16: 43-91.

Olias P., Gruber A.D., Hafez H.M., Heydorn A.O., Mehlhorn H., Lierz M. 2010b: Sarcocystis calchasi sp. nov. of the domestic pigeon (Columba livia f. domestica) and the Northern goshawk (Accipiter gentilis): light and electron microscopical characteristics. Parasitol. Res. 106: 577-585.

Olias P., Gruber A.D., Kohls A., Hafez H.M., Heydorn A.O., Mehlhorn H., Lierz M. 2010a: Sarcocystis species lethal for domestic pigeons. Emerg. Infect. Dis. 16: 497-499.

Olias P., Olias L., Krücken J., Lierz M., Gruber A.D. 2011: High prevalence of Sarcocystis calchasi sporocysts in European Accipiter hawks. Vet. Parasitol. 175: 230-236.

Olias P., Olias L., Lierz M., Mehlhorn H., Gruber A.D. 2010c: Sarcocystis calchasi is distinct to Sarcocystis columbae sp. nov. from the wood pigeon (Columba palumbus) and Sarcocystis sp. from the sparrowhawk (Accipiter nisus). Vet. Parasitol. 171: 7-14.

PAK S.M., Eshtokina N.V. 1984: [Sarcosporidians of birds.] In: Panin V.J. (Ed.), Sarcosporidians of Animals in Kazakhstan. Nauka, Alma-Ata, Kazakhstan, pp. 150-168. (In Russian.)

Prakas P., Butkauskas D., Sruoga A., Švažas S., Kutkienė L. 2011b: Identification of Sarcocystis columbae in wood pigeons (Columba palumbus) in Lithuania. Vet. Med. Zoot. 55: 33-39.

Prakas P., Kutkienė L., Butkauskas D., Sruoga A., Žalakevičius M. 2013: Molecular and morphological investigations of Sarcocystis corvusi $\mathrm{sp}$. nov. from the jackdaw (Corvus monedula). Parasitol. Res 112: 1163-1167.

Prakas P., Kutkienė L., Sruoga A., Butkauskas D. 2011a: Sarcocystis $\mathrm{sp}$. from the herring gull (Larus argentatus) identity to Sarcocystis wobeseri based on cyst morphology and DNA results. Parasitol. Res. 109: 1603-1608.

Ronquist F., Huelsenbeck J.P. 2003: MrBayes 3: Bayesian phylogenetic inference under mixed models. Bioinformatics 19: $1572-1574$

Smith J.H., Neill P.J., Dillard E.A. 3rd, Box E.D. 1990. Pathology of experimental Sarcocystis falcatula infections of canaries (Serinus canaries) and pigeons (Columba livia). J. Parasitol. 76: 59-68.

Tamura K., Nei M., Kumar S. 2004: Prospects for inferring very large phylogenies by using the neighbor-joining method. Proc. Natl. Acad. Sci. USA. 101: 11030-11035.

Tamura K., Peterson D., Peterson N., Stecher G., Nei M., KumAR S. 2011: MEGA5: molecular evolutionary genetics analysis using maximum likelihood, evolutionary distance, and maximum parsimony methods. Mol. Biol. Evol. 28: 2731-2739.

Wobeser G., Leighton F.A., Cawthorn R.J. 1981: Occurrence of Sarcocystis Lankester, 1882, in wild geese in Saskatchewan. Can. J. Zool. 59: 1621-1624. 